Comparative Philosophy Volume 10, No. 1 (2019): 208-212

Open Access / ISSN 2151-6014 / www.comparativephilosophy.org

https://doi.org/10.31979/2151-6014(2019).100114

CONSTRUCTIVE ENGAGEMENT DIALOGUE (2.2)

\title{
DISAGREEMENT AND CONVERGENCE ON THE CASE OF LATIN AMERICAN PHILOSOPHY, FOR EXAMPLE: REPLY TO CARLOS PEREDA AND ROBERT SANCHEZ
}

\author{
MANUEL VARGAS
}

Whether as a target of interesting disagreement, or as tool that can be refined, extended, or even implemented, to have one's ideas taken up is perhaps the happiest fate of any bit of philosophical work. So, it is with some gratitude that I have this opportunity to reflect on some recent discussion of my "On the Value of Philosophy: The Latin American Case" (2010). I focus on two articles: Robert Sanchez's wideranging and challenging "Strengthening the Case for Latin American Philosophy" (2014), and Carlos Pereda's exquisitely titled and richly developed "On Mexican Philosophy, For Example" (2019, in this journal). Despite the appearance of disagreement between the parties, the exchange makes clear that there is considerable convergence amongst us about the value of Latin American philosophy.

\section{VALUE IN MARGINALITY}

In "On the Value of Philosophy: The Latin American Case" (2010) I took up the question of whether there is any reason for philosophers in the United States (and the rest of the Anglophone world) to pay attention to philosophy produced in Latin America. The argument in that article was that (surprise!) there is value in Latin American philosophy, that it serves the various philosophical interests we ordinarily have in philosophy, and moreover, that reflection on the history of philosophy in Latin America suggests that it is a good place to look for underappreciated resources for helping us address questions in Anglophone philosophical projects.

Although I maintain that philosophy in Latin America is often enough interesting in and of itself, the weight of the argument in that article turned on a picture of about the value of philosophy, and the value of philosophical traditions outside of one's own (in this case- the Anglophone philosophical canon, however that is construed). The idea was that a cursory look at the history of philosophy in Latin America reveals

VARGAS, MANUEL: Professor of Philosophy, University of California at San Diego, USA. Email: mrvargas@ucsd.edu 
examples that anticipate ideas that we now regard as valuable in Anglophone philosophy that this fact gives us reason to think that philosophical work produced in Latin American philosophy is not merely unoriginal, derivative dreck. Thus, counter to its (perhaps still common) perception, Latin America philosophy is a storehouse of complex cultural objects - philosophical ideas, theories, distinctions - that satisfy the standard of philosophical interestingness internal to wide swaths of Anglophone philosophy.

Were I to re-write the article today, I would emphasize a point that is continuous with the above, but not made explicit in the original article. This picture-of philosophy as a kind of cultural resource, and of Latin American philosophy as plausibly meeting standards of prima facie philosophical value - also means that there are plausibly distinctive resources in Latin American philosophy precisely because the history of philosophy unfolded differently. There are sometimes ideas, or combinations of ideas, that did not occur in the Anglophone canon in the same way, and that had different roles in the economy of philosophy. This fact is valuable both for its own sake, and for the light it can cast on what is contingent and perhaps an available alternative to our current configurations of convictions.

In sum, this double fact, of Latin American philosophy's value in the way that all philosophy is valuable (roughly, as a kind of cultural resource in domains where we lack convergence on methods and truths) and as a set of resources with its own history, configuration, and development, is the basis for arguing that there is good prima facie reason for Anglophone philosophers to think that there is something of recognizable value to be found in the study of Latin American philosophy.

\section{REFLECTIONS ON A FIRST ENGAGEMENT}

Robert Sanchez (2014) objects to the foregoing account on at least two grounds. First, he maintains that by arguing that philosophy in Latin America has the value that all philosophy has, effectively demotivates Anglophone philosophers from studying it because there is no special reason to study it. The crucial impediment is the fact of finite attention. Simply noting that some bit of philosophy is valuable qua philosophy is not a reason to prioritize its study, nor a reason to alter standing conceptions of the canon. Second, he argues that the account "overlooks philosophy's capacity to call into question or disrupt an entire culture or tradition" (4). In particular, he claims that this picture of philosophy's value cannot account for the value of Socratic irony as "disruptive or destructive" and as "disobedience, a suspension, or a disruption" of the existing culture (5).

On the matter of the first point, Sanchez is obviously right that disciplinary attention is finite, so simply noting that Latin American philosophy is valuable (that it can be original, prescient, interesting, and so on) is not by itself sufficient to capture the attention of the typical Anglophone philosopher.

My ambition in "On the Value of Philosophy" was not to explain why there is a special or unique value in Latin American philosophy (although I gestured at one way to extend those arguments in that direction, above). Rather, my goal was to make it 
plausible that there are valuable things there to be found there, if someone wants to look there. My interest was not to make a decisive argument that showed that philosophers in the Anglophone world must necessarily attend to philosophy from Latin America. I am not sure there is any argument that can do that. My goal was to make it easier for others to argue (in their papers, their classrooms, in their hiring meetings) that the arguably default presumption in the Anglophone profession that there is nothing interesting or valuable in Latin American philosophy ought to be replaced with a different default assumption, namely, that there is something interesting and valuable there.

This is a modest argument, but I like to think it is not entirely useless to have made it explicit. Even so, Sanchez wasn't wrong to note its limits, and to insist that many philosophers working in Latin American philosophy would want to argue for something much stronger, namely, that there is a special value in Latin American philosophy. Above, I gestured at one consideration that seems to bolster the prospects for that aspiration: inasmuch as Latin American philosophy has its own history, its own configuration of ideas, and its own original work, there is good reason to think it can help us see things that we do not already see about matters we already have good reason to care about. This is not a fully fleshed-out argument, here or in the earlier article, but it is very much in keeping with the Sanchez's concern.

Even so, this too is a limited argument, in that it is not intended to exclude the possibility of other, better, or more compelling arguments. It does give us an overarching receipt for generating more detailed arguments in this vein, however. Pick your favorite topics (especially in social and cultural philosophy), do a real dive into Latin American philosophy, and you are bound to find alternatives that force us to reconsider what otherwise might have struck us (qua Anglophone philosophers) as fixed, given, or certain in their configuration, historical motive, or effective deployment.

What more is required to capture disciplinary attention in Anglophone philosophy? I doubt there is a single answer to this question for all times, places, and purposes. One strategy among many is to show our Anglophone colleagues how figures and ideas rooted in Latin America help us make sense of issues and ideas that already matter in our shared philosophical world. This is a strategy I have recommended and pursued elsewhere (for example, Vargas forthcoming a; Vargas forthcoming $b$ ).

Even if it is effective, it is unlikely to be the only effective strategy. Translation, highlighting curricular and enrollment pressures, growing familiarity with what there is in Latin American philosophy, and shifting sense of what is canonical and what is profitably counter-canonical (Cf. Rickless 2018, Vargas forthcoming b), and so on, each offer opportunities for shifting disciplinary attention. In short, I agree with Sanchez that showing the value of a bit of philosophy does not guarantee attention for that work. It is, however, a first step (although maybe not much more than that) towards answering the "Why bother?" question that has sometimes affected the reception of work outside Anglophone philosophy (Cf. Pereda 2019). 
With respect to Sanchez's second objection, that my account fails to capture the Sanchez's preferred story about the value of philosophy-that is, Socratic irony understood as a broadly skeptical, critical stance to a culture or tradition-it is helpful to turn to some recent reflections by Carlos Pereda.

\section{REFLECTIONS ON A SECOND ENGAGEMENT}

In a recent article in this journal, Carlos Pereda makes a sustained and compelling case for the value of Mexican philosophy, and Latin American philosophy more generally, as a tool for expanding and enriching the philosophical tradition as it is understood outside of Latin America (and within parts of Latin America).

I find myself in the happy position of agreeing with a great deal of what Pereda says. ${ }^{1} \mathrm{He}$ is surely right that our understanding of various abstract questions in philosophy can be profitably informed by intentionally considering phenomena from different levels of abstraction and by contrasting it with phenomena adjacent to those that are our central concerns. He calls these efforts the "strategy of passages" and the "strategy of detours," respectively. His thought is that philosophy that exhibits these characteristics (i.e., "nomadic thought") is especially fruitful. One can find such philosophy in Mexican philosophy, for example. He cites the work of Luis Villoro as a particularly lucid instance. So, there is good reason to attend to Mexican and Latin American philosophy as it has successfully incorporated both the universal and culturally specific.

Pereda considers whether his picture of nomadic thought's products can be profitably understood as providing a kind of cultural resource of the sort that figures in my (2010) account. His answer is a tentative yes, but he goes on to take up an interpretive issue that arises in Sanchez (2010). Pereda notes that my anchoring the value of philosophy in a story about cultural resources - anything that assists in the flourishing, survival, or perpetuation of a given culture-can be interpreted as

\footnotetext{
${ }^{1}$ Perhaps the one place where we might have a substantive disagreement concerns whether there is a version of the universalists vs cultural particularists debate that cannot be dissolved in the way he recommends. I think there is at least one version of the debate that resists his dissolution: the historicism vs. anti-historicism debate. It is not obvious what Pereda thinks about that version of the debate, at least not in his (2019) piece. So, although I share with Pereda the thought that many fights between important versions of the "univeralist vs. culturalist" debates in the middle parts of the $20^{\text {th }}$ century in Latin America were confused or fundamentally misconceived, the historicist/anti-historicist one seems to me more fundamental and more difficult to dissolve in the way he suggests. That said, I do think there is a kind of intermediate position available to us that fits well with much of what Pereda says. The view is this: we can make at least some important headway on philosophical issues without having to re-litigate the historicist/anti-historicist fight on every philosophical topic (Cf. Sánchez 2018). Even the most dogged anti-historicist must allow that we can intelligibly ask questions about the philosophical import about the local, the particular, and the situated. There are reasonable and interesting questions to ask about social ontology, and the mapping of socially and culturally particular worlds, and the various normative pressures that arise within those worlds. Of course, it will be difficult to follow these threads out to their most fundamental grounds without taking a stand on the historicist/anti-historicist debate, but on the position I just sketched, we can do a good deal of valuable and interesting philosophy before then.
} 
narrowly concerned with affirming a local conceptual or cultural configuration, where this does not include the disruptive, skeptical, critical attitude that characterizes Socratic irony. As Pereda notes, this is how Sanchez appears to interpret my account.

Pereda rightly observes that this is not a view I have to hold (142). Indeed, I do not hold it. Pereda goes on to argue that the most plausible reading of the role of philosophy-as-cultural-resource is one according to which critical, disruptive, and therapeutic versions of philosophy count as cultural resources, too. I concur. There is no reason why the important things identified by Sanchez - the sometimes disruptive, destabilizing features of philosophy - are not themselves important cultural resources.

So, in the end, I think we have an agreeable equilibrium point between the three of us. One way philosophy can be valuable is by challenging our received cultural and conceptual presumptions. Latin American philosophy, in virtue of its history and manner of development, as well as its distinct (relative to most of Anglophone philosophy's) place of origin has important and plausibly distinctive resources for challenging the cultural and conceptual presumptions of Anglophone philosophy. So, again, it is plausible to think that Latin American philosophy is valuable in both the general way that good philosophy is valuable. It is also plausibly valuable for disrupting or challenging our received views about culture, thought, and the world.

\section{REFERENCES}

Pereda, Carlos (2019), “On Mexican Philosophy, For Example”, Comparative Philosophy 10.1: 193-208.

Rickless, Samuel C. (2018), "Brief for an Inclusive Anti-Canon", Metaphilosophy 49.1-2: 167-81.

Sanchez, Robert E. (2014), "Strengthening the Case for Latin American Philosophy: Beyond Cultural Resources", APA Newsletter on Hispanic/Latino Issues 13.2: 1-9.

Sánchez, Carlos (2018), "The Gift of Mexican Historicism”, Continental Philosophy Review 51.3: $439-57$.

Vargas, Manuel (2010), “The Value of Philosophy: The Latin American Case”, Comparative Philosophy 1.1: 33-52.

- (forthcoming a), "The Philosophy of Accidentality", The Journal of the American Philosophical Association.

- (forthcoming b), "Canonical Philosophy, Mexican Philosophy", APA Newsletter on Hispanic/Latino Issues. 